British Journal of Medicine \& Medical Research

15(10): 1-7, 2016, Article no.BJMMR.24412

ISSN: 2231-0614, NLM ID: 101570965

SCIENCEDOMAIN international

www.sciencedomain.org

\title{
An Evaluation of 605 Endoscopic Examination in a Rural Setting, Lacor Hospital in Northern Uganda
}

\author{
T. R. Okello ${ }^{1 *}$, D. M. Ogwang ${ }^{1}$, N. O. Alema ${ }^{2}$ and I. Pecorella ${ }^{3}$ \\ ${ }^{1}$ Consultant Surgeon, St Mary's Hospital Lacor, Honorary Lecturer, Department of Surgery, \\ Gulu University Medical School, Uganda. \\ ${ }^{2}$ Consultant Surgeon and Honorary Lecturer in Surgery, Uganda. \\ ${ }^{3}$ Department of Radiological, Oncological and Anatomic Pathology Sciences, University of Rome \\ "Sapienza", Viale Regina Elena, 324 - 00161, Rome, Italy.
}

Authors' contributions

This work was carried out in collaboration between all authors. Author TRO designed the study, wrote the protocol and wrote the first draft of the manuscript. Author DMO managed the literature searches and review and discussion. Author NOA did analyses of the study and critique of write-up. Author IP managed the samples. All authors read and approved the final manuscript.

Article Information

DOI: 10.9734/BJMMR/2016/24412

Editor(s):

(1) S. U. Fuhong, ICU Laboratory, Erasme Hospital, Free University Brussels, Brussels, Belgium.

Reviewers:

(1) Somchai Amornyotin, Mahidol University, Bangkok, Thailand.

(2) Ramesh Gurunathan, Tuanku Jaafar Hospital, Malaysia. Complete Peer review History: http://sciencedomain.org/review-history/14646

Original Research Article

Received $19^{\text {th }}$ January 2016

Accepted $7^{\text {th }}$ April 2016

Published $16^{\text {th }}$ May 2016

\section{ABSTRACT}

Introduction: The aim of this study was to evaluate the profile of esophagogastroduodenal (EGDS) diseases diagnosed by upper endoscopy in a rural area of Uganda in a retro-protective study of 605 patients.

Results: The mean age of patients with digestive symptoms was 39.7yrs (SD +/-16.11) and female gender predominated by $60 \%$ compared to the male ( $P$ value 0.000 ). Peasant farmers were the commonest group with GI symptoms requiring EGDS compared to the rest $72.1 \%$ v $27.9 \%$. Epigastric pain was the commonest indication (58\%) for EGDS, followed by chest pain (11\%), abdominal pain $(8.8 \%)$, dyspahgia (7.6\%) and hematemesis $(7.3 \%)$. The commonest endoscopy finding was gastritis $(47.9 \%)$ followed by esophagitis $(14.4 \%)$, cancer esophagus $(5.1 \%)$, esophageal varicose (4\%), PUD (2.3\%), gastric cancer (1\%). However $19.5 \%$ of patients had normal EGDS. There was a significant correlation between the outpatient diagnosis and 
endoscopy finding ( $P$ value $0.01, r=0.144$ ) and between endoscopy finding and histology findings ( $\mathrm{P}$ value $0.001, r=0.236$ ). H. pylori was positive in $53 \%$ of patients with gastritis.

Conclusion: Gastritis is the commonest lesion (47.9\%) of which $53 \%$ have $H$ pylori and Cancer esophagus account for $5.1 \%$ of Gl lesion in our setting. Cancer stomach is rare in our setting.

Keywords: Upper Gi-endoscopy; indication; findings; gastritis; peptic ulcer; H. pylori.

\section{INTRODUCTION}

Endoscopy is the ideal procedure for identifying organic diseases of the foregut and its practice is influenced by epidemiology of gastrointestinal (GI) diseases [1]. Results from endoscopic exam allow association of Esophagogastroduodenal (EGDS) findings with patient presentation and extrapolation of the findings to patient population in clinical practice, outside of traditional medical centers [2]. Although 39\% of EGDS performed have inappropriate indications, better diagnostic yield depend appropriateness, patient gender and age, treatment setting, and symptoms [3]. Indications for EGDS vary from region to region and many authors have found varying proportions of indications for endoscopy.

Dyspepsia represent the commonest indication in the USA, Pakistan and Ethiopia $[4,5,6]$ as well as in Nigeria and is followed by upper gastrointestinal bleeding [7]. However, epigastralgia was found to represent the commonest indication for EDGS (47.7\%) and it is followed by diffuse abdominal pain (21.8\%) and repeat procedure (19.1\%) [8]. In Uganda Okello (2006) [9] also found the main indications to comprise of epigastric pain (67.4\%), dyspepsia (11.9), hematemesis (8.9\%), recurrent abdominal pain $(3 \%)$, recurrent vomiting $(3 \%)$, and miscellaneous (5.8\%). In epigastralgia, $39 \%$ of procedures lead to the discovery of disease [8].

Despite the varying indications, most studies have reported anecdotal proportion of GI lesions depending on the regions. In Canada, Peptic Ulcer Disease (PUD) account for $7.5 \%$ of EGDS finding, celiac disease (2.5\%), and upper gastrointestinal cancer $0.9 \%$ [10]. However in Lagos Nigeria, the commonest endoscopic findings are; gastroesophageal reflux disease, followed by gastroduodenitis [11]. While in Togo, the most common lesions consist of PUD $(34.2 \%)$, inflammatory disease such as esophagitis, gastritis, bulboduodenitis (32.4\%), gastroduodenal bile reflux (9.3\%), pylorobulbar stenosis $(5.5 \%)$, tumoral disease $(3.7 \%)$, and esophageal varicosities (3.7\%) [8]. In Kenya gastritis is the most common EGDS finding
(25.8\%) [12]. In Uganda Okello [9] found duodenal ulcer in $14.8 \%$ of adolescents and gastritis in $12.6 \%$, duodenal scarring (5.2\%), bile reflux $(5.2 \%)$ duodenitis (4.4\%). In their EGDS series, the prevalence of $H$. pylori was found to be $37.4 \%$ in Uganda and cigarette smoking, poor sanitation, and lack of formal education were the predisposing factors [13]. However there is need to evaluate endoscopy in a rural post conflict community and associate the finding with patient presentation in clinical practice.

\subsection{Objective}

To describe the profile of esophagogastroduodenal (EGDS) diseases diagnosed by upper digestive tract endoscopy (UDTE) in a rural area of Uganda and relate it to the histological findings and $H$. pylori.

\section{METHODS AND MATERIALS}

This retro- prospective study was carried out from Jan 2015 to July 2015 in order to investigate the endoscopic findings in 605 patients who presented to St Mary's Hospital Lacor a large rural based University teaching general hospital with 483 bed located in Northern Uganda. Currently the Hospital has two general surgeons who perform over 1200 upper Gl endoscopy per year and each of the surgeons has over 10years experience in EGDS.

All patients with upper gastrointestinal symptoms were first assessed in the out patients unit by a clinician who discretionally decided to book and counsel him/her for EDGS as an elective case in manner standardized manner. On the day of scoping, inform consent was obtained from the patients priory. Those who consented were consecutively recruited and interviewed by the endoscopist to discern the main indication for EGDS and its duration. They were then given lidocaine $1 \%$ to gurgle in their throat for 510 minutes as these causes local numbness in the pharynx and mouth. During the procedure, the endoscopist notes and records the findings and when necessary takes punch biopsy for immediate fixation in standard formalin and send 
for histology. The pathologist was required to examine and report on the histology finding as well as $H$. pylori presence after standard staining method with H\&E and Giemsa stains. Only patients who could not tolerate the EDGS procedure were excluded. The following variables were obtained and analysed using SPSS version 15 to determine the pattern of esophagogastroduodenal presentation and diseases: Age, Gender, Occupation, indication, Outpatient diagnosis, Endoscopy finding, Histology findings, Presence of malignant cancer, and H Pylori presence.

\section{RESULTS}

\subsection{Biographic Data}

Approximate 605 patients were enrolled in the study. From Table 1, the age of patients ranged from 5 to 89 yrs old, mean age 39.7 year (SD+/16.11). The majority of patients with gastrointestinal complaints that required EGDS are the youth of $19-35 \mathrm{yrs}$ old $(39 \%, \mathrm{n}=605)$ and Adults of age group $36-65$ yrs $(47 \%, n=605)$. For all the age groups, the female gender predominated in patients undergoing EGDS procedure and overall a significant majority of patient undergoing EGDS in our setting are females $60 \%$ compared with their male counterpart $(40 \%),(P$ value 0.000$)$. However regarding their occupation, $436(72.1 \%)$ were peasant farmers, followed by students $10.7 \%$, teachers $(3.6 \%)$ and business men/women (3.5\%). Therefore, peasant farmers significantly constitute the biggest proportion of patients who have $\mathrm{Gl}$ symptoms requiring EGDS ( $P$ value $0.000, \chi^{2}=3295.754$ ).

Regarding indications for EGDS, the commonest indication was epigastric pain (58\%), followed by chest pain $(11 \%)$, abdominal pain $(8.8 \%)$, dysphagia to solids/liquids (7.6\%), and hematemesis (7.3\%) [Table 2]. Dyspepsia which is rather a vague presentation constituted only $0.7 \%, \quad(n=605)$ of the indications. Dyspepsia, anemia, lower abdominal pain, hemoptysis and repeat endoscopy were the least common indication for EGDS.

Table 3 shows the clinical diagnosis made by the examining clinician based on the medical presentation of the patients in the outpatients (OPD) or referring unit. The most common diagnosis made in medical clinical practice in our setting was gastritis (65\%), followed by cancer esophagus (6.3\%), Gastroesophageal Reflux Disease (GERD) (5.3\%), peptic ulcer disease (PUD) (4.6\%), esophagitis (4.6\%) and esophageal varices $(2.5 \%)$. Hence the more diagnosis of gastritis made, the more the outpatient move away from PUD. The least common OPD diagnosis made by clinicians was duodenitis. However in $3.5 \%$ of instances the clinician could not make a diagnosis.

Table 1. Biographic data of endoscopy patients

\begin{tabular}{llll}
\hline & Male & \multicolumn{1}{c}{ Female } & Total \\
\hline $\begin{array}{l}\text { Age group } \\
\text { Child [0-10yrs] }\end{array}$ & $1(25 \%)$ & $3(75 \%)$ & 4 \\
$\begin{array}{l}\text { Adolescents } \\
\text { [11-18yrs] }\end{array}$ & $13(31 \%)$ & $29(69 \%)$ & 42 \\
Youth [19-35yrs] & $102(43 \%)$ & $133(57 \%)$ & 235 \\
Adults & $109(39 \%)$ & $173(61 \%)$ & 282 \\
[36-65yrs] & & & \\
Elderly $\geq 66 y r s$ & $18(43 \%)$ & $24(57 \%)$ & 42 \\
& $\mathbf{2 4 3 ( 4 0 \% )}$ & $\mathbf{3 6 2}(60 \%)$ & $\mathbf{6 0 5}$ \\
\hline Occupation & Frequency & Percent & \\
\hline Peasant & 436 & 72.1 & \\
Student & 65 & 10.7 & \\
Teacher & 22 & 3.6 & \\
Health worker & 12 & 2 & \\
Business & 21 & 3.5 & \\
Tailor & 5 & 0.8 & \\
Carpenter & 1 & 0.2 & \\
Askari & 2 & 0.3 & \\
Others & 35 & 5.8 & \\
Armed forces & 1 & 0.2 & \\
Fisherman & 1 & 0.2 & \\
Civil servant & 4 & 0.7 & \\
Total & $\mathbf{6 0 5}$ & $\mathbf{1 0 0 \%}$ & \\
\hline
\end{tabular}

Table 2. Indication for endoscopy

\begin{tabular}{lll}
\hline Indication & Frequency & Percent (\%) \\
\hline Epigastric pain & 351 & 58 \\
Hematemesis & 44 & 7.3 \\
Vomiting & 12 & 2 \\
Dysphagia & 46 & 7.6 \\
Ordinopagia & 7 & 1.2 \\
Dyspepsia & 4 & 0.7 \\
Control (Review) & 1 & 0.2 \\
endoscope & & \\
Abdominal pain & 53 & 8.8 \\
Throat pain & 11 & 1.8 \\
Chest pain & 67 & 11.1 \\
Malena stool & 5 & 0.8 \\
Anemia & 1 & 0.2 \\
Lower Abd. pain & 1 & 0.2 \\
Hemoptysis & 2 & 0.3 \\
Total & $\mathbf{6 0 5}$ & $\mathbf{1 0 0}$ \\
\hline
\end{tabular}


Table 3. Outpatient diagnosis

\begin{tabular}{lll}
\hline OPD diagnosis & Frequency & Percent \\
\hline PUD & 28 & 4.6 \\
Gastritis & 393 & 65 \\
Esophagistis & 28 & 4.6 \\
Upper GI bleed UGIB & 15 & 2.5 \\
Esophageal varices & 16 & 2.6 \\
Duodenitis & 1 & 0.2 \\
GERD & 32 & 5.3 \\
Ca esophagus & 38 & 6.3 \\
Ca stomach & 8 & 1.3 \\
GOO & 5 & 0.8 \\
None & 21 & 3.5 \\
Achalasia & 2 & 0.4 \\
Blood disorder & 2 & 0.3 \\
Bile reflux & 2 & 0.3 \\
Pancreatitis & 5 & 0.8 \\
Esophageal stricture & 4 & 0.7 \\
Diabates miletus & 1 & 0.2 \\
Pluerisy & 2 & 0.3 \\
Anemia & 2 & 0.3 \\
Total & $\mathbf{6 0 5}$ & $\mathbf{1 0 0}$ \\
\hline
\end{tabular}

Whereas the clinician made diagnosis basing on the clinical presentation and referred the patient for EDGS, out of the 605 patients studied, the endoscopist found gastritis (47.9\%) to be the commonest condition affecting gastrointestinal symptoms patients in our community. This was followed by esophagitis (14.4\%), cancer esophagus $(5.1 \%)$, esophageal varicose $(4 \%)$ and PUD (2.3\%), (Table 4). Whereas $19.5 \%$ of patients who were scoped were found to be normal, hiatus hernia and cancer stomach accounted for the least lesion found that is, only $1 \%$ of the upper Gi diseases in our setting respectively. There was a significant correlation between the outpatient diagnosis and endoscopy finding, ( $P$ value $0.01, r=0.144)$. Therefore in our clinical setting with paucity of resources, clinician could initiate treated without waiting for endoscopy results.

Table 5 shows that a total of 121 biopsies representing 20\% ( $n=605)$, were done. When the histology finding is compared with the endoscopy findings, there was a significant correlation between them ( $P$ value $0.01, r=0.236$ ). However out of the 88 biopsies of gastric mucosa done, 47 $(53 \%)$ had $H$. Pylori present and of the 2 PUDs that were biopsied, 1 was positive for $H$. pylori. However $H$. pylori was negative in patients with ca esophagus, duodenitis, gastric polyp and gastric adenomai. Therefore our finding avers that H.pylori infection was most commonly associated with gastritis.
Table 4. Endoscopy findings

\begin{tabular}{lll}
\hline Endoscopy findings & Frequency & Percent \\
\hline PUD & 14 & 2.3 \\
Gastritis & 290 & 47.9 \\
Esophagistis & 87 & 14.4 \\
Ca esophagus & 31 & 5.1 \\
Esophageal varices & 24 & 4 \\
GERD & 16 & 2.6 \\
Duodenitis & 4 & 0.7 \\
Ca stomach & 6 & 1 \\
Haitus hernia & 6 & 1 \\
Normal & 118 & 19.5 \\
Deformed duodenal bulb & 3 & 0.5 \\
Gastric polyp & 2 & 0.3 \\
Esophageal stricture & 1 & 0.2 \\
Ca tongue & 1 & 0.2 \\
mallory weiss tear & 1 & 0.2 \\
Achalasia & 1 & 0.2 \\
Total & $\mathbf{6 0 5}$ & $\mathbf{1 0 0}$ \\
\hline
\end{tabular}

Table 5. Helicobacter pylori presence

\begin{tabular}{lllll}
\hline & \multicolumn{4}{c}{$\begin{array}{c}\text { H. pylori } \\
\text { present }\end{array}$} \\
\cline { 2 - 5 } & No & Yes & NA & Total \\
\hline PUD & 1 & 1 & 0 & 2 \\
Gastritis & $40(47 \%)$ & $47(53 \%)$ & 1 & 88 \\
duodenitis & 1 & 0 & 1 & 2 \\
Ca & 25 & 0 & 3 & 28 \\
esophagus & & & & \\
Ca stomach & 0 & 0 & 1 & 1 \\
$\begin{array}{l}\text { Normal } \\
\text { Not }\end{array}$ & 2 & 0 & 1 & 3 \\
$\begin{array}{l}\text { Applicable } \\
\text { (NA) }\end{array}$ & 1 & 0 & 476 & 477 \\
$\begin{array}{l}\text { Severe } \\
\text { dysplasia }\end{array}$ & 0 & 0 & & \\
$\begin{array}{l}\text { Hyperplasti } \\
\text { C Polyp }\end{array}$ & 2 & 0 & 0 & 2 \\
$\begin{array}{l}\text { Gastric } \\
\text { adenoma }\end{array}$ & 1 & 0 & 0 & 1 \\
Total & $\mathbf{7 3}$ & $\mathbf{4 8}$ & $\mathbf{4 8 4}$ & $\mathbf{6 0 5}$ \\
\hline
\end{tabular}

\section{DISCUSSION}

Endoscopy remains a powerful tool in diagnosis and management of $\mathrm{Gl}$ conditions. In this study of Esophagogastroduodenoscopy (EGDS), the mean age of patients requiring the procedure was 39.7year ( $\left.S D_{+} /-16.11\right)$ which is similar to the mean age of 37.7 years (range: $15-84$ years) reported by Djibril et al. 2009 [8]. Like in this study, many other others have found a higher female preponderance over their male counterpart in Nigeria, Togo and Uganda respectively $[7,8,9]$. Perhaps this relate to the female patients' better health seeking behavior compared to their male counterpart. Peasant farming was a significantly predominant 
occupation amongst the 605 patients studied $(P$ value 0.000 ). In our setting peasant farmers are often poor people leaving in areas with poor sanitation and most often lack formal education. Tsongo et al. [13], found that poor sanitation, and lack of formal education constitute significant predisposition factors to $H$. Pylori infection.

The indications for EGDS vary with patients' description of what they feel. Whereas most studies found dyspepsia to be the leading indication $[5,7,8]$ this study found epigastric pain to be the leading indication for EGDS (58\%). Epigastralgia was also reported to be the leading indication of EGDS by Olokoba et al. [7] and Okello [9]. Most patients in our setting are able to finger point to their epigastrium as painful part and hence the reason for them requiring EGDS. With respect to the indication, the examining clinician had to make a diagnosis prior to referring the patient for EGDS. The most common diagnosis made in medical clinical practice in our setting was gastritis $(65 \%)$, followed by cancer esophagus (6.3\%) Gastroesophageal Reflux Disease (GERD) (5.3\%), peptic ulcer disease (PUD) (4.6\%), esophagitis $(4.6 \%)$ and esophageal varices $(2.5 \%)$. There was a positive significant correlation between OPD diagnoses $(P$ value $0.01, r=0.144)$ and EGDS findings. Accuracy of diagnosis relates to experience and expertise of the clinician and it helps to reduce patient anguish and save resources because treatment can be initiated based on clinical diagnosis.

Endoscopically, the commonest lesion identified was gastritis (47.9\%) followed by esophagitis (14.4\%), cancer esophagus (5.1\%), esophageal varicose (4\%), PUD (2.3\%) and $19.5 \%(n=605)$ of patients who were scoped were normal. These findings had a positive and significant correlation to the histological findings, ( $P$ value 0.001, $r=$ 0.236). Therefore endoscopist working in our setting could diagnose most of the Gl disorders based on their examination alone. The rate of gastritis in this study is higher than most other studies, for example, in a student health center study by Schroeder [15] in Scandinavia, reported overall gastritis rate of $22.1 \%$. The risk factors for $H$. Pylori infection [13] tend to mirror that of gastritis. Whilst Lodenyo, Rana, Mutuma, Kabanga, Kuria et al. [14] found gastritis rate of $25.8 \%$ in Kenya, $6 \%$ was reported in Ethiopia [6] and $12.6 \%$ in Uganda [9]. Whereas Gherasim and Dranga [16] attributes gastritis to chronic alcohol consumption, amount and frequency, our predominantly peasant community often suffer poor sanitation and lack of education on top of chronic alcohol ingestion in "sackets" as crude spirits. These risk factors combined predispose to high rates of $H$ pylori infection [13], cancer esophagus as well as liver diseases. The low rate of PUD found in this study is congruent to fact that the disease has demonstrated a decreasing prevalence and incidence over the years globally as well as in the Philippines $[17,18]$. More than half $(53 \%, n=88)$ of the gastric and PUD $(50 \%, n=2)$ biopsies showed presence of $H$. Pylori. The association between $H$. pylori and gastritis has been found by other researchers in Brazil and Germany as well [19, 20]. Furthermore, the severer the gastritis the more difficult to eradicate $H$. Pylori [21], yet their safe eradication is necessary for the prevention of gastric cancer [22]. The high prevalence of Hepatitis B infection in our community [23] makes liver disease, chronic alcoholism, esophageal lesion more precarious, hence the high rate of esophageal varicose However cancer stomach is rare in our setting (1\%).

\section{LIMITATION}

The major limitation experienced in the study was related to 5 cases whose tissue histology could not be read, this was caused by a wrong formalin concentration supplied, but such cases were excluded from the study. The other limitation was related to difficulty in follow-up of the cases that met the inclusion criteria, but this was circumvented by using a cross-section survey.

\section{CONCLUSION}

The female gender, youth and adults who are poor peasants predominate amongst patients with upper digestive tract symptoms requiring EGDS. Whereas $19.5 \%$ their EGDS is normal, gastritis represent commonest lesion in them $(47.9 \%)$ and $53 \%$ of the gastritis have $\mathrm{H}$ pylori. Cancer esophagus which accounted for $5.1 \%$ of Gl lesion is also important ailment in our setting but cancer stomach is rare in our environment.

\section{RECOMMENDATION}

Clinician in resource limited areas could initiate treatment basing on clinical diagnosis since there is a correlation between clinical diagnosis, endoscopy and histological findings as this will reduce unnecessary referral and suffering of the patient. Treating of gastritis should aim at eradicating $H$ pylori. 


\section{ETHICAL APPROVAL}

It is not applicable.

\section{COMPETING INTERESTS}

Authors have declared that no competing interests exist.

\section{REFERENCES}

1. Gyedu A, Yorke J. Upper gastrointestinal endoscopy in the patient population of Kumasi, Ghana: Indications and findings The Pan African Medical Journal. 2014; 18(327):4806. ISSN 1937-8688.

DOI: $10.11604 /$ pamj

2. Brintha KE, Gralnek IM, Mattek $\mathrm{N}$, Lieberman DA, Eisen G. An evaluation of endoscopic indications and findings related to nonvariceal upper-GI hemorrhage in a large multicenter consortium. Gastrointestinal Endoscopy 2008;67(3):422-429.

DOI: http://dx.doi.org/10.1016/j.gie.2007.09 .024

3. Froehlich F, Repond C, Müllhaupt B, Vader JP, Burnand B, et al. Is the diagnostic yield of upper Gl endoscopy improved by the use of explicit panel-based appropriateness criteria, Gastrointestinal Endoscopy. 2000;52(3):333-341.

4. Lieberman DA, De Garmo PL, Fleischer $D E$, Eisen GM, Helfand M. Patterns of endoscopy use in the United States, Gastroenterology. 2000;118(3):619-624.

Doi: 10.1016/S0016-5085(00)70269-1

5. Khurram M, Khaar HT, Hasan Z, Umar M, Javed S, et al. A 12 years audit of upper gastrointestinal endoscopic procedures (PMID:12814528). Journal of the College of Physicians and SurgeonsPakistan. 2003;13(6):321-32.

6. Taye M, Kassa E, Mengesha B, Gemechu T, Tsega E, Upper gastrointestinal endoscopy: A review of 10,000 cases. Ethiop Med J. 2004:42(2):97-107.

7. Olokoba AB, Olokoba LB, Jimoh AA, Salawu FK, Danburam A, et al. Upper gastrointestinal tract endoscopy indications in northern Nigeria. J Coll Physicians Surg Pak. 2009,19(5):327-8.

DOI: 05.2009/JCPSP.327328

8. Djibril MA, M'Ba KB, Kaaga $Y L$, Bagny $A$, Edou KA, et al. Upper digestive tract Endoscopy in Rural Africa, Togo, Med Trop (Mars). 2009;69(1):48-50.
9. Okello TR. Upper gastrointestinal endoscopic findings in adolescents at Lacor Hospital, Uganda. Afr Health Sci. 2006;6(1):39-42.

10. Kolber M, Szafran O, Suwal J, Diaz M, Outcomes of 1949 endoscopic procedures: Performed by a Canadian rural family physician. Can Fam Physician. 2009; 55(2):170-5.

11. Onyekwere CA, Hameed $\mathrm{H}$, Anomneze EE, Chibututu C. Upper gastrointestinal endoscopy findings in Nigerians: A review of 170 cases in Lagos. Niger Postgrad Med J. 2008;15(2):126-9.

12. Lodenyo H, Rana F, Mutuma GZ, Kabanga JM, Kuria JK, et al. Patterns of upper gastrointestinal diseases based on endoscopy in the period 1998-2001. Afr J Health Sci. 2005;12(1-2):49-54.

13. Tsongo L, Nakavuma J, Mugasa C, Kamalha E. Helicobacter pylori among patients with symptoms of gastroduodenal ulcer disease in rural Uganda. Infect Ecol Epidemiol. 2015;5:26785.

14. Lodenyo H, Rana F, Mutuma GZ, Kabanga JM, Kuria JK, et al. Patterns of upper gastrointestinal diseases based on endoscopy in the period 1998-2001. Afr J Health Sci. 2005;12(1-2):49-54.

15. Schroeder $\mathrm{P}$, Upper gastrointestinal endoscopy at a student health centre, Scand J Prim Health Care. 1990;8(4):1915.

16. Gherasim S, Dranga M, Clinicoepidemiological assessments for establishing the relationship between alcohol consumption and gastritis. Observations in Dorohoi area, Botosani county. Rev Med Chir Soc Med Nat lasi. 2010;114(1):47-51.

17. Sung JJ, Kuipers EJ, El-Serag HB, Systematic review: The global incidence and prevalence of peptic ulcer disease. Aliment Pharmacol Ther. 2009;29(9): 938-46.

DOI: 10.1111/j.1365-2036.2009.03960.x

18. Wong SN, Sollano JD, Chan MM, Carpio RE, Tady CS, et al. Changing trends in peptic ulcer prevalence in a tertiary care setting in the Philippines: A seven-year study. J Gastroenterol Hepatol. 2005; 20(4):628-32.

19. Bahú, da Graça SM, da Silveira, Reverbel T, Maguilnick et al. Endoscopic nodular gastritis: An endoscopic indicator of highgrade bacterial colonization and severe gastritis in children with Helicobacter pylori. 
Journal of Pediatric Gastroenterology \& Nutrition. 2003;36(2):217-222.

20. Weck MN, Stegmaier C, Rothenbacher D. Brenner $H$. Epidemiology of chronic atrophic gastritis: Population-based study among 9444 older adults from Germany, Alimentary Pharmacology \& Therapeutics. 2007;26(6):879-887.

DOI: 10.1111/j.1365-2036.2007.03430.x

21. Kalkan IH, Sapmaz F, Güliter S, Atasoy P. Severe gastritis decreases success rate of
Helicobacter pylori eradication. Wien Klin Wochenschr; 2015.

22. Leontiadis GI, Ford AC, Helicobacter pylori eradication: Gastric cancer prevention. BMJ Clin Evid. 2015;Pii:0406.

23. Ochola E, Ocama P, Orach CG, Nankinga ZK, Joan N, Kalyango JN, et al. High burden of hepatitis B infection in Northern Uganda: Results of a population-based survey BMC Public Health. 2013;13:727. DOI: 10.1186/1471-2458-13-727.

(c) 2016 Okello et al.; This is an Open Access article distributed under the terms of the Creative Commons Attribution License (http://creativecommons.org/licenses/by/4.0), which permits unrestricted use, distribution, and reproduction in any medium, provided the original work is properly cited.

Peer-review history:

The peer review history for this paper can be accessed here: http://sciencedomain.org/review-history/14646 